\title{
Neuronal Processes That Underlie Expression of Kindled Epileptiform Events in the Piriform Cortex in vivo
}

\author{
Lewis B. Haberly', and Thomas P. Sutula ${ }^{2,3}$ \\ 'Department of Anatomy, ${ }^{2}$ Neuroscience Training Program, and ${ }^{3}$ Department of Neurology, University of Wisconsin, \\ Madison, Wisconsin 53706
}

Recent studies with kindling and convulsant drug models of epilepsy suggest that the piriform (primary olfactory) cortex may be particularly susceptible to generation of epileptiform activity. The present study has examined the generation of interictal epileptiform events in the piriform cortex of kindled rats in vivo, taking advantage of special features of this system that facilitate physiological analysis. The investigation included analysis of extracellular and intracellular potentials, and membrane currents computed by current source density (CSD) analysis. In pyramidal cells, epileptiform events consisted of an initial EPSP that occurred in all-or-none fashion and a long-lasting IPSP with $\mathrm{Cl}^{-}$- and $\mathrm{K}^{+}$-mediated components. Onset of the IPSP was sufficiently fast that firing evoked by the EPSP was consistently limited to single action potentials. CSD analysis revealed the presence of two distinctly different excitatory epileptiform currents: an initial inward current of unknown origin that is widely distributed over depth, and a second much larger inward current at the depths of proximal apical and basal dendrites of pyramidal cells. It was concluded that this second component is mediated by the associational projections of pyramidal cells excited by the first component. Since these heavy associational projections also extend to neighboring areas including the amygdala, entorhinal cortex, and insular and orbitofrontal areas of neocortex, this second component could be widely propagated within the basal forebrain. An important finding was that the EPSP generated by this associational pathway was completely blocked in cell bodies of pyramidal cells in piriform cortex by the IPSP during most events. This IPSP may therefore play a critical role in limiting seizure activity by preventing reverberating positive feedback in the pyramidal cell population. It can be speculated that compromise of this IPSP, as by repetitive activation by the shock trains used for kindling, leads to prolonged epileptic activity in the piriform cortex and the many limbic structures to which it projects.

\footnotetext{
Received Aug. 9, 1991; revised Jan. 7, 1992; accepted Jan. 9, 1992.

We thank Kevin Ketchum for contributions to the development of the CSD analysis methods and for consultations on interpretations, Kerry Woodbury and Matthew Wilson for writing the software, and José Cavazos, Golijeh Golarai, and He Xiao-Xian for kindling the animals. This work was supported by NINDS Grants NS19865 (L.B.H.) and NS25020 (T.P.S.).

Correspondence should be addressed to Lewis B. Haberly, Department of Anatomy, University of Wisconsin, 1300 University Avenue, West Loading Dock, Madison, WI 53706.

Copyright (C) 1992 Society for Neuroscience $0270-6474 / 92 / 122211-14 \$ 05.00 / 0$
}

Recent studies have raised the possibility that the piriform (primary olfactory) cortex may play a larger role in temporal lobe epilepsy than previously suspected. Injection of convulsant drugs into many temporal lobe structures can induce seizures, but the threshold for initiation is much lower at the deep boundary of piriform cortex than in the hippocampus, entorhinal cortex, amygdala, and other areas that have been implicated in the generation of epileptic events (Piredda and Gale, 1985, 1986). Injection of convulsant drugs into deep piriform cortex induces seizures that resemble those in complex partial epilepsy.

A number of studies with the kindling model of epilepsy have provided further evidence for a role of piriform cortex in temporal lobe epileptogenesis: the majority of interictal discharges in kindled rats occur at shorter latency in the piriform cortex than in the hippocampal formation, amygdala, and other temporal lobe areas, regardless of the site of induction (Kairiss et al., 1984; Racine et al., 1988). Kindling occurs after fewer afterdischarges in the piriform cortex than in the hippocampal formation and other limbic structures (Goddard et al., 1969). Injection of excitatory amino acid antagonists (Croucher et al., 1988) and GABA transaminase inhibitors (Stevens et al., 1988) into the deep piriform cortex suppresses kindling and kindled seizures from other parts of the limbic system. In slices taken from kindled animals, epileptiform activity cannot be evoked in the hippocampal formation unless extracellular $\mathrm{K}^{+}$is elevated or inhibition is reduced (Kairiss et al., 1984; King et al., 1985), but can be readily evoked in the piriform cortex in normal bathing medium (McIntyre and Wong, 1986; Hoffman and $\mathrm{Ha}-$ berly, 1991b). Finally, an analysis of latency suggests that epileptiform activity in the piriform cortex may propagate to other temporal lobe structures (Racine et al., 1988).

The present study was designed to analyze the mechanism of generation of epileptiform activity in the piriform cortex of kindled rats. A urethane-anesthetized preparation was used in which kindled epileptiform activity can be consistently evoked by shock stimulation. Spontaneous interictal and evoked activity in this preparation resembles that previously observed in chronic unanesthetized animals (Kairiss et al., 1984; Russell and Stripling, 1985; Racine et al., 1988). In this acute preparation it is possible to perform detailed physiological analysis with intracellular recording and current source density (CSD) methods. CSD analysis has proven to be of particular value for study of this system (Haberly and Shepherd, 1973; Moyano et al., 1985; Rodriguez and Haberly, 1989) because the segregation of neuronal elements over depth (reviewed by Haberly, 1985; Haberly and Bower, 1989) facilitates the interpretation of net membrane currents. This study in intact animals focuses on the 
mechanism of expression of kindled scizures; induction and initiation processes are being examined in a parallel series of studies in a slice preparation (Hoffman and Haberly, 1989a,b, $1991 \mathrm{a}, \mathrm{b})$.

\section{Materials and Methods}

Kindling procedure. Kindled seizures were induced by repetitive stimulation delivered through bipolar electrodes made from $150-\mu \mathrm{m}$-diameter stainless steel wire that were chronically implanted in the granule cell layer of the olfactory bulb of male Sprague-Dawley rats. Surgery was performed under pentobarbital anesthesia at an initial intraperitoneal dose of $60 \mathrm{mg} / \mathrm{kg}$ with supplements as necessary. After a 2 week recovery period, kindling was performed with $1 \mathrm{sec}$ duration trains of $1 \mathrm{msec}$ biphasic square pulses at $62 \mathrm{~Hz}$, adjusted to the lowest amplitude that evoked an afterdischarge. The stimulus trains were delivered twice daily, $5 \mathrm{~d}$ /week; evoked behavioral and electrographic seizures were classified according to standard techniques (Sutula and Steward, 1986). Electrophysiological investigation was performed in animals that had experienced 12-100 generalized tonic clonic (class 5) seizures at intervals ranging from 2 to $114 \mathrm{~d}$ after the last evoked seizure. After completion of electrophysiological recording, placements of stimulating and recording electrodes were verified histologically in $40 \mu \mathrm{m}$ frozen sections stained with cresyl violet.

General recording procedures. All recording was carried out under urethane anesthesia at an initial intraperitoneal dose of $1.2 \mathrm{~g} / \mathrm{kg}$ with supplements as necessary. Animals were tracheotomized but not artificially respirated; temperature was maintained with a thermostatically controlled warming blanket; one-half normal physiological saline with $5 \%$ dextrose was infused intragastrically at a rate of $1 \mathrm{ml} / \mathrm{hr}$ throughout experiments. Electrodes were introduced under direct vision after surgical exposure of the cortical surface. Afferent fibers in the lateral olfactory tract (LOT) were stimulated with $100 \mu \mathrm{sec}$ current pulses delivered through a monopolar tungsten microelectrode referenced to a nearby large-diameter silver wire contacting muscle. In most cases, the stimulating electrode was introduced through the intact dura with the tip just penetrating the surface. Placement was over the thick central portion of the tract to minimize current spread to the underlying cortex. The ability of this electrode to selectively activate afferent fibers was verified by determining that the $\mathrm{B}_{1}$ component of the field potential was blocked by a conditioning shock delivered $30-60 \mathrm{msec}$ before the test shock (see Haberly, 1973). Recording electrodes were micropipettes of varying tip diameter and filling solution as described below.

Procedures for intracellular recording. Recording micropipettes were filled with neutralized 4 м potassium acetate; resistances were 80-100 M $\Omega$. The brain surface was stabilized by minimizing the skull opening ( $\leq 1 \mathrm{~mm}$ in diameter), by introducing electrodes through small slits in the dura at an oblique angle, and by covering the surface with $4 \%$ agar in mammalian Ringer. Cell entry was facilitated with current pulses of varying waveform and amplitude. Current was injected through a bridge circuit to alter membrane potential, but the relatively high electrode capacitance resulting from the layer of agar and the considerable penetration depth usually prevented accurate adjustment of bridge balance. Responses were recorded and analyzed with a computer system as previously described (Tseng and Haberly, 1988). Laminar positions of impalements were determined from the characteristic shapes of extracellular field potentials evoked by LOT stimulation (Haberly, 1973; Rodriguez and Haberly, 1989). Population epileptiform events were monitored by recording field potentials at the cortical surface near the site of entry of the intracellular micropipette. Because large extracellular field potentials are associated with epileptiform activity, it was necessary to subtract responses recorded after electrode withdrawal from responses recorded intracellularly to compute the responses of impaled neurons (see Kandel et al., 1961, their Fig. 3). Extracellular records were selected for subtraction based on a malch in simultaneously recorded surface field potentials with those recorded when the electrode was intracellular.

Procedures for CSD analysis. Methods and theoretical basis for onedimensional CSD analysis in piriform cortex with a single electrode have been previously described in detail (Haberly and Shepherd, 1973; Rodriguez and Haberly, 1989). The following brief description includes recent minor changes. The recording micropipette was broken to an outside tip diameter of $1.5-3 \mu \mathrm{m}$ and filled with $4 \%$ Chicago blue. Micropipette depth was controlled with a piezoelectric manipulator with optical reader head (Burleigh). The cortical surface was stabilized with $4 \%$ agar in mammalian Ringer's solution. Data acquisition and analysis were automated using an IBM-compatible PC (386/20) and Tecmar Labmaster A/D-D/A card. Stimulus parameters were adjusted so that epileptiform components were evoked with a consistent waveform and latency (not possible in all animals). Consistency was insured by monitoring potentials with a second electrode at a fixed depth during data acquisition. In experiments where epileptiform events failed to occur on all trials, nonepileptiform responses were manually rejected during acquisition. However, all reported results were obtained in experiments in which no rejection was required.

Current source density was computed from sets of extracellular field potentials evoked by LOT stimulation that were recorded at $20 \mu \mathrm{m}$ intervals through the depth of the cortex. Typically, two to four responses of $600 \mathrm{msec}$ duration were averaged on line at each of 55-70 depths. The first step in the analysis was the generation from these responses of potential profiles over depth at small time intervals. To improve signal-to-noise ratio, three or more sets of potential profiles from successive penetrations at the same recording site were typically averaged. These profiles were then smoothed with a convolution kernel defined in the spatial frequency domain by a Blackman window, double differentiated, and plotted as three-dimensional surfaces, contour plots, or depth and time rasters. Amplitudes of sources and sinks were integrated over depth and compared at small time increments to ensure that net current flow was one-dimensional. Source-sink mismatch was typically less than $5 \%$ when smoothing was minimal. Statistical analysis was performed on sets of data derived from multiple penetrations at each recording site as previously described (Rodriguez and Haberly, 1989). Correspondence between cortical laminae and CSD profiles was established from three dye marks placed in each penetration. Marks were made by iontophoresis of Chicago blue from the recording micropipette $(+1 \mu \mathrm{A}$ for 5-10 min); animals were immediately perfused with $4 \%$ formaldehyde in $0.9 \% \mathrm{NaCl}$, the brain sectioned with a vibratome, and wet-mounted sections drawn with a camera lucida. Defocusing the condenser and use of dark-field illumination allowed visualization of all layers including the layer $\mathrm{Ia} / \mathrm{Ib}$ boundary. Sectioning with a vibratome eliminated shrinkage introduced by the cryoprotection that is required for frozen sectioning; use of wet mounts eliminated distortion at the cortical surface introduced when sections are dried onto coated slides.

\section{Results}

\section{Kindling alters field potentials evoked by afferent fiber stimulation}

As previously described for the opossum (Rodriguez and $\mathrm{Ha}$ berly, 1989), shock stimulation of afferent fibers in the LOT of control rats $(n=5)$ evoked a triphasic field potential response throughout the piriform cortex (Fig. 1A). This response consisted of an initial deep positive wave (period 1) followed by a deep negative wave (period 2), and a long-lasting deep positive wave (period 3 ). Approximately mirror image potentials were recorded from layer $I$.

Period 1 consisted of $\mathrm{A}_{1}$ and $\mathrm{B}_{1}$ components (Fig. $1 A$, right column). The $A_{1}$ component has been shown to result from current that generates the monosynaptic EPSP; the $\mathrm{B}_{1}$ component, from current that generates the disynaptic association fiber-evoked EPSP (Rodriguez and Haberly, 1989). Chlorideand potassium-mediated IPSPs occur during periods 2 and 3 (Satou et al., 1982; Tseng and Haberly, 1988).

Kindling induced complex changes in the field potential evoked by LOT stimulation (Fig. $1 B)(n=14$ animals). Typically, responses that closely resembled those in control animals were interspersed with responses with added components (Fig. 2). These added components originated at variable latency, usually late in period 1 or early in period $2(15-50 \mathrm{msec})$. Although probability of occurrence of abnormal components was increased at higher shock strengths, amplitude was not continuously graded as a function of stimulus strength as in the normal evoked potential. Abnormal components were observed in all kindled animals, regardless of the number of class 5 seizures 
Slow Sweep
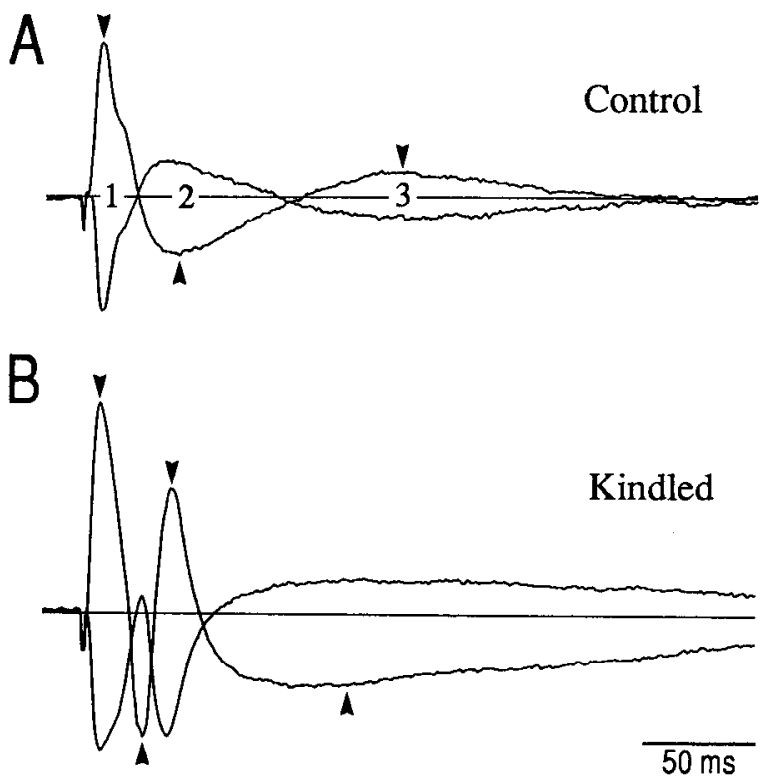

Fast Sweep
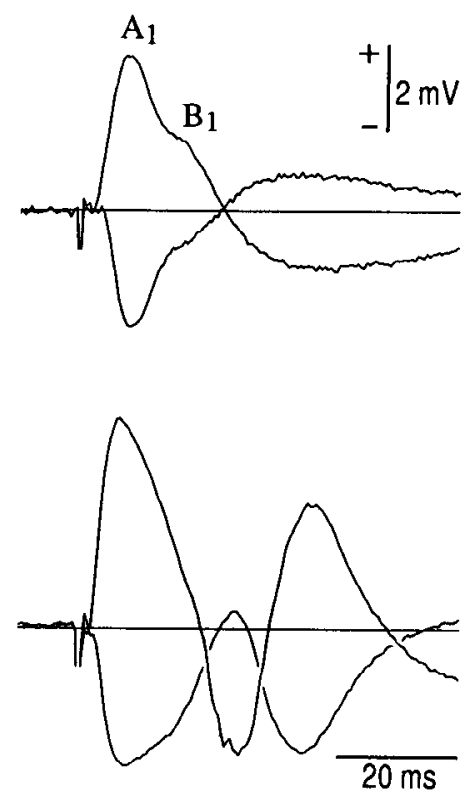

Figure 1. Averaged field potentials recorded at the surface and in the superficial part of layer III of posterior piriform cortex in response to LOT stimulation in control and kindled rats. The same records are illustrated at slow (left) and fast (right) sweep speeds. $A$, Control. Successive response phases are numbered as described in Results; $A_{i}$ and $B_{I}$ denote early and late components of period 1. $B$, Example of the most commonly observed response form in kindled rats with nearly mirrorimage waveforms at surface and deep recording sites. Crossover points in the fast sweep record have been retouched for clarity. $s$, surface; $d$, deep. Traces are averages of three or more responses. Records from deep sites are indicated by arrowheads.
(12-100) or delay after last afterdischarge before recording (2$144 \mathrm{~d})$.

The waveform of abnormal response components varied over a broad range, but typically included a triphasic negative-positive-negative sequence in deep layers of posterior piriform cortex and corresponding opposite polarity response at the cortical surface (Fig. 1B). The initial deep negative abnormal response component was often spike-like ("epilept. spike" in Fig. 3), especially when it occurred at relatively brief latency, but could also have a slow ramp-like onset (Fig. 4C). Response averaging often revealed a small deep positive deflection that preceded the negative wave (arrowhead in Fig. 3A). In contrast to the variable negative wave, the waveform of the following deep positive component was relatively consistent and usually resembled that of the initial nonepileptiform response component (Fig. 4, left column). The final component consisted of a deep negative wave that varied greatly in form. In some cases this component was of sufficient amplitude and duration so that period 3 of the field potential was obscured. This can be seen in Figure $1 B$ (left column), where the final deep negative component outlasted the deep positive component in control responses (Fig. $1 A$ ) that defines period 3 . Similar abnormal potentials could also be evoked by stimulation of association fibers in layers Ib-III of piriform cortex (not illustrated). In animals that had undergone a large number of kindled seizures, abnormal components evoked in posterior piriform cortex by moderate strength shocks could be consistent in latency and waveform, allowing CSD analysis to be performed as described below.

An infrequently recorded response that was not included in the present study consisted of an abnormal component at brief latency that was only clearly visible in deep layers. Preliminary results (L. B. Haberly and T. Sutula, unpublished observations) indicate that this short-latency component represents a graded increase in pyramidal cell firing and is not epileptiform in character like later components.

Triphasic abnormal potentials were also observed in anterior piriform cortex. Although waveform often resembled the typical form described above for posterior piriform cortex, the positive component frequently failed to cross the nonepileptiform baseline, reducing the response to two deep negative waves (Fig. $5 C$. bottom trace).

The probability of occurrence of abnormal potentials was dependent on the rate of stimulation. In most experiments,

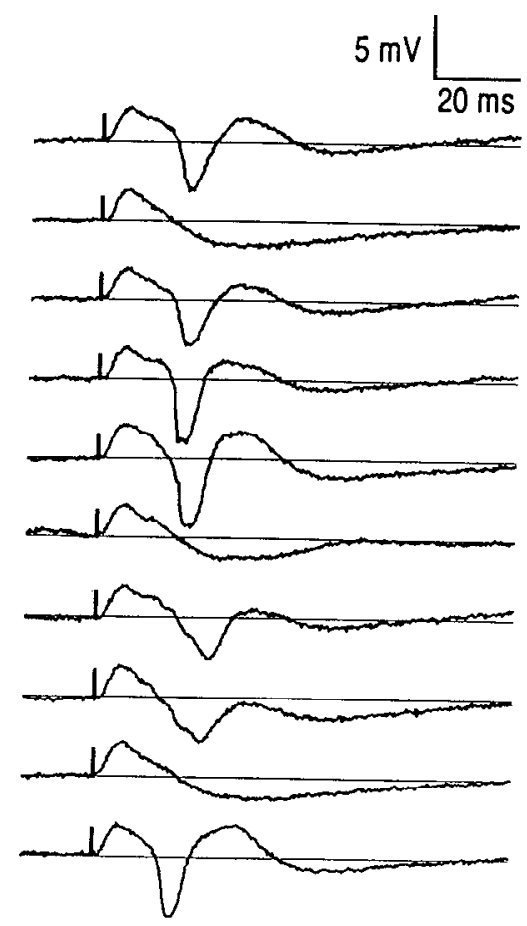

Figure 2. Successive responses from the superficial part of layer III in posterior piriform cortex with shock strength adjusted to threshold for epileptiform response components. Note the alternation between responses resembling those in control animals (Fig. $1 A$ ) and those with large epileptiform components (Fig. $1 B$ ). Also note the varying waveform and amplitude of epileptiform activity. Such variability could be minimized in most experiments by adjustment of stimulus intensity and rate. 
Dependence on stimulus rate

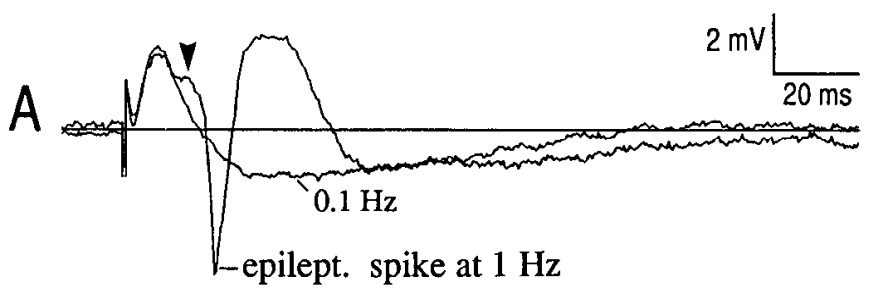

Paired shocks facilitate occurrence

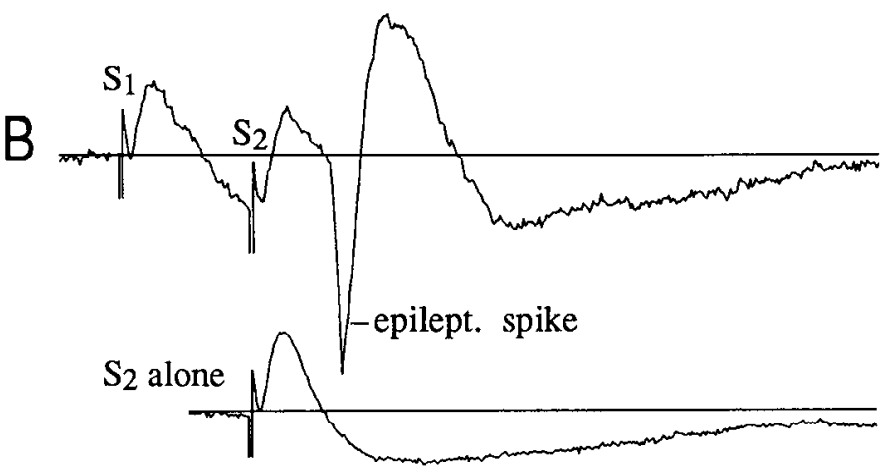

Figure 3. Probability of occurrence of epileptiform events is a function of stimulus rate and is increased by pairing shocks. $A$, Superimposed responses from the superficial part of layer III in posterior piriform cortex to identical LOT shocks presented at $1 \mathrm{~Hz}$ and $0.1 \mathrm{~Hz}$ as indicated. $B$, Comparison of response to a single shock (bottom trace) with response to the same shock when preceded by an identical conditioning shock at an interval of $30 \mathrm{msec}$ (top trace). Pairing shocks consistently increased the probability of occurrence and amplitude of epileptiform events. All traces are averages of three or more responses, with the exception of the top trace in $B$, which is a single response. $S_{1}$ and $S_{2}$ are first and second shocks. Calibration in $A$ applies to all traces.

epileptiform events were most frequently evoked with a stimulus repetition rate on the order of $1 \mathrm{~Hz}$; rates of $0.1 \mathrm{~Hz}$ or below were often ineffective (Fig. $3 A$ ). Paired shocks were much morc cffcctive in cvoking abnormal potentials than single shocks
(Fig. 3B). Although effects of variations in paired shock separation were not systematically studied, intershock intervals on the order of $30 \mathrm{msec}$ were usually optimal. Abnormal events evoked by paired shocks consistently displayed a large spikelike deep negative component (Fig. 3B).

\section{Control responses}

In unoperated control animals under identical $(n=8)$ or ncarly identical ( $n>50$ ) recording conditions, high-amplitude, consistently evoked "abnormal" response components as described above were never observed. Previous studies (Kairiss et al., 1984; Russell and Stripling, 1985) have established that chronic electrode implantation in the olfactory bulb and other limbic structures, and application of the same number of shocks used for kindling but at a low rate fail to induce changes in evoked potentials in piriform cortex like those observed after kindling.

\section{Spontaneous epileptiform events occur in kindled animals}

In the absence of stimulation, triphasic field potentials often occurred spontaneously in kindled animals. These potentials typically displayed considerable variability, but the different forms resembled the abnormal response components evoked by LOT stimulation (Fig. 4).

Based on their generation in the absence of stimulation, erratic nature, and tendency for all-or-none occurrence in response to shock stimulation, the abnormal potentials in kindled animals can be said to be epileptiform in character. They resemble potentials recorded in chronic unanesthetized preparations (compare with Racine et al., 1983, their Fig. 7, and Kairiss et al., 1984, their Fig. 8).

\section{Simultaneous rostral-caudal recording}

Since epileptiform events were observed in both anterior and posterior parts of the piriform cortex, simultaneous two-site recording was carried out to determine if activity in these two regions is temporally related. The recording sites in these experiments were separated by approximately $1 \mathrm{~cm}$. Shock strength and repetition rate were adjusted so that epileptiform events were infrequent to minimize coincidental occurrence at both sites. When well-defined epileptiform events were evoked in
Evoked

A

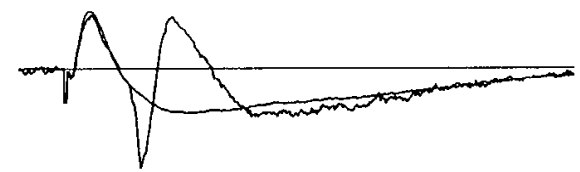

Figure 4. Comparison of epileptiform events evoked by LOT stimulation in the superficial part of layer III in posterior piriform cortex (left) with those occurring spontaneously at the same site in the absence of stimulation (right). The full range of variation recorded is represented from top to bottom in terms of increasing latency for evoked potentials and decreasing amplitude for spontaneous potentials. Individual evoked epileptiform responses are superimposed on averaged responses with no detectable epileptiform components. Calibration applies to all traces.
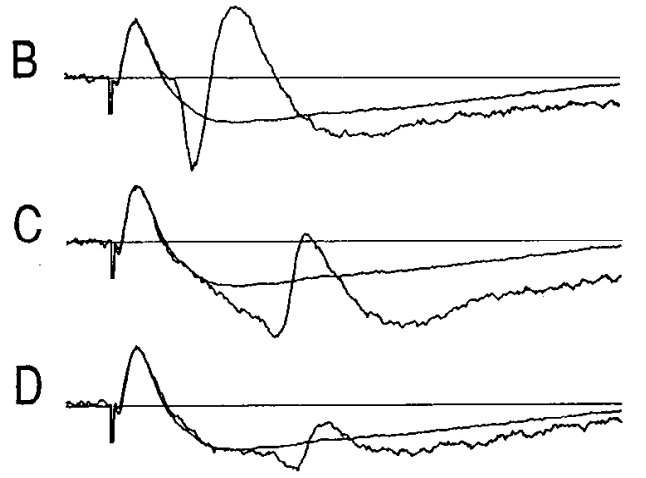

\section{Spontaneous}
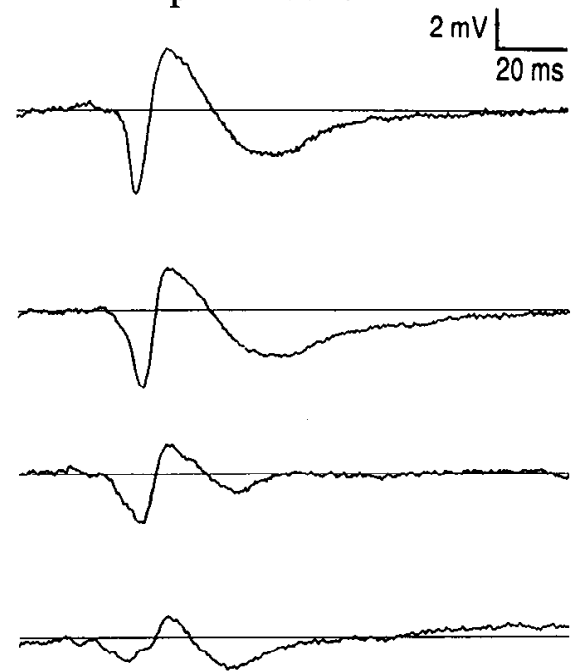
posterior piriform cortex with this frequency constraint, welldefined events also occurred in anterior piriform cortex in 71 of 79 trials in three animals. Amplitudes and durations of the initial high amplitude components could be greater at either anterior or posterior sites (compare Fig. $5 A, B$ ). In 70 of 71 trials with events at both sites, latencies were greater in anterior than in posterior piriform cortex, suggesting possible posterior-toanterior propagation. Apparent conduction velocity computed from latency to peak for the 35 trials in which sharply defined deep negative components were present at anterior and posterior sites was $0.80 \pm 0.13 \mathrm{~m} / \mathrm{sec}( \pm \mathrm{SD})$.

By the use of relatively strong or paired shocks, it was possible to evoke epileptiform events at both anterior and posterior sites with the anterior event at shorter latency. Unfortunately, since threshold for epileptiform events tended to be lower posteriorly, it was not possible to determine if this temporal relationship was the result of independent generation at the two sites or a causal relationship such as anterior to posterior propagation. However, many anterior events were observed without subsequent posterior events, indicating that if anterior-to-posterior propagation does occur, it is inconsistent.

\section{Intracellular analysis}

Control responses. Responses to stimulation of afferent fibers in urethane-anesthetized control rats ( $n=17$ cells in five animals) consisted of initial depolarizing and long-lasting hyperpolarizing components as previously described in a variety of preparations (Biedenbach and Stevens, 1969; Scholfield, 1978; Satou et al., 1982; Haberly and Bower, 1984; Tseng and Haberly, 1988). Although cells were not labeled by dye injection, comparison with responses recorded from identified cells (Haberly and Bower, 1984; Tseng and Haberly, 1988), as well as the lack of nonpyramidal cell impalements in previous in vivo studies in this laboratory (Haberly and Bower, 1984; Haberly et al., 1987) suggest that most or all neurons studied in control and kindled rats were pyramidal cells.

Responses after kindling. In kindled animals, intracellularly recorded responses to afferent fiber stimulation were qualitatively indistinguishable from controls when no epileptiform components were apparent in simultaneously recorded field potentials (Fig. 6B). However, when epileptiform events occurred in extracellular records, both initial depolarizing and long-lasting hyperpolarizing potentials were substantially increased in amplitude (Fig. 6A,C,D) $(n=11$ cells in four animals that were stable for $>1 \mathrm{hr}$ and a much larger number of transiently stable impalements).

Depolarizing epileptiform component. During early epileptiform events (initiated in period 1), most cells displayed a sharply peaked depolarizing potential that evoked action potentials when threshold was exceeded (Fig. 6A,D). The rising phase of this potential correlated with the surface positive, deep negative abnormal component of the epileptiform field potential (compare Fig. $6 C, E$ ). Termination was usually abrupt as consequence of the onset of a fast IPSP as described below. However, when epileptiform events were evoked at relatively long latency, a long-lasting depolarizing envelope was occasionally observed, apparently as a result of a delay or decrease in this IPSP (trace 3 in Fig. $7 A$ ).

Several lines of evidence indicate that an EPSP underlies the epileptiform depolarization in pyramidal cells. First, it is excitatory in action as evidenced by the triggering of action potentials (Fig. 6D). Second, injection of hyperpolarizing current
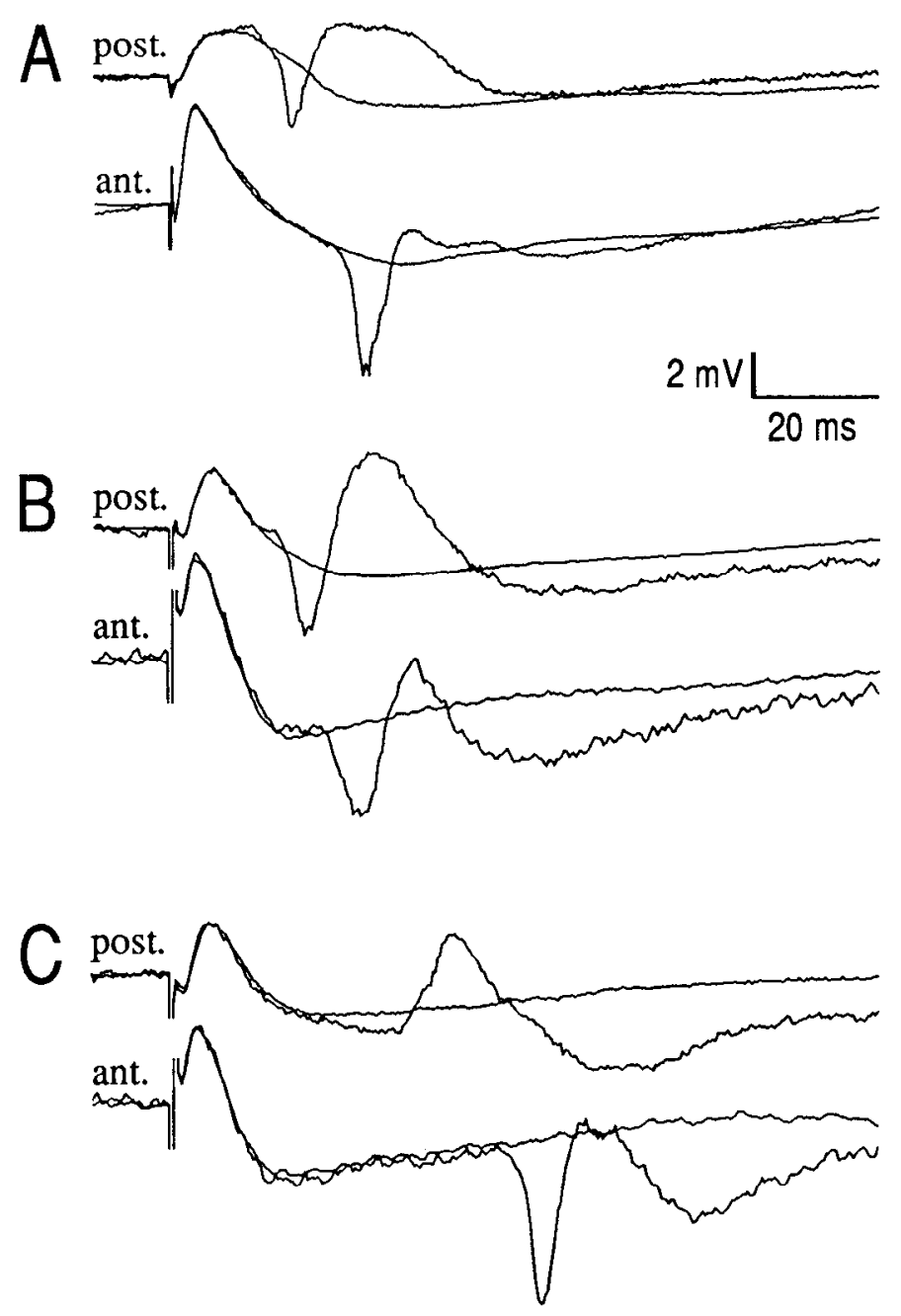

Figure 5. Apparent propagation of epileptiform activity within piriform cortex. Responses are pairs of simultaneously recorded responses to LOT stimulation from layer III in anterior and posterior parts of piriform cortex. Individual responses with epileptiform components are superimposed on averaged responses without epileptiform activity. Responses in $B$ and $C$ were from the same sites with epileptiform events at different latencies. Recording electrodes were separated by $10 \mathrm{~mm}$ in $A$ and $9 \mathrm{~mm}$ in $B$ and $C$. Calibration applies to all responses.

increased the amplitude of epileptiform depolarizing potentials, and injection of depolarizing current decreased the amplitude, consistent with an EPSP (Fig. 8A). Third, occurrence of this intracellular potential was consistently accompanied by epileptiform events at comparable latency in simultaneously recorded field potentials, indicating the presence of an underlying "population" rather than single cell "endogenous" process (Figs. 68). Fourth, occurrence was not blocked by sustained depolarization-a manipulation that blocks the low-threshold inactivating $\mathrm{Ca}^{2+}$ current that can generate slow "spikes" in piriform cortex (Tseng and Haberly, 1989b). Occasional occurrencc of epileptiform depolarizations at long latency during hyperpolarizing IPSPs (Fig. $8 B$ ) further rules out exclusive generation by endogenous potentials triggered by the initial graded EPSP.

Hyperpolarizing epileptiform components. A striking feature was the rapidity with which the epileptiform EPSP was terminated-sufficiently fast so that firing was consistently limited to a single spike. Several observations indicate that this termination process is a $\mathrm{Cl}^{-}$-mediated IPSP generated via a feedback 

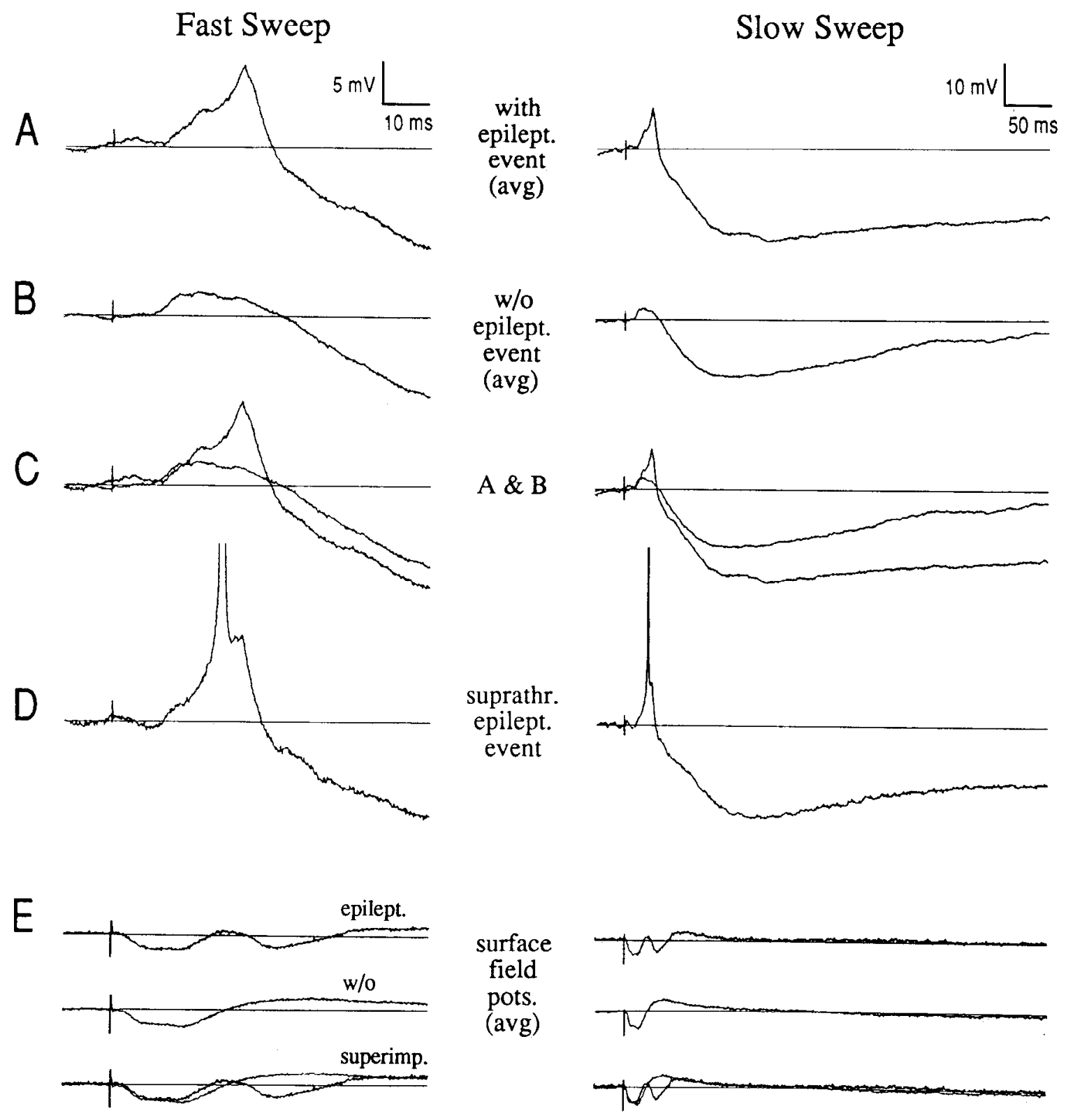

$$
\begin{aligned}
& \text { w/o } \\
& \text { epilept. } \\
& \text { event } \\
& \text { (avg) }
\end{aligned}
$$

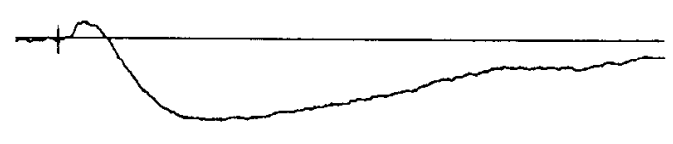

A \& B

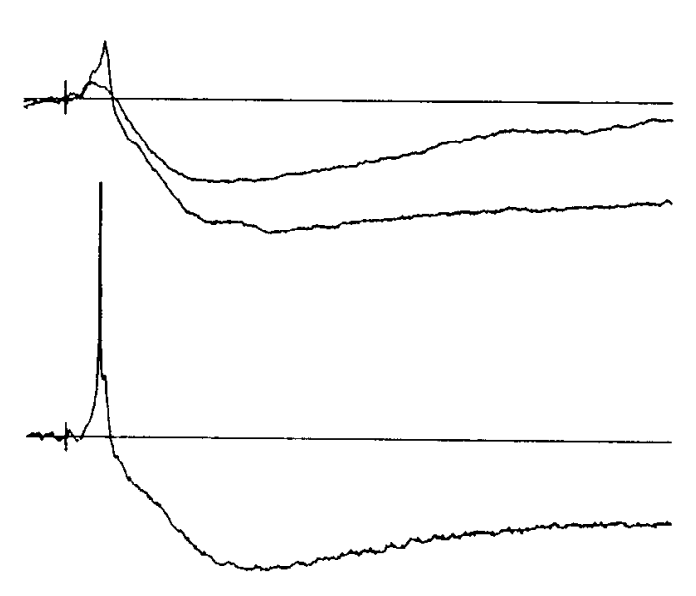

suprathr. epilept. event

surface field pots. (avg)

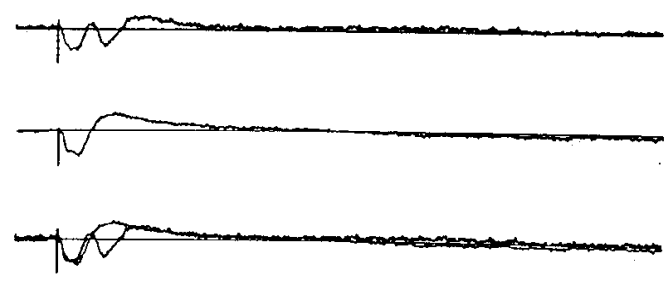

Figure 6. Intracellularly recorded responses from a probable pyramidal cell in posterior piriform cortex of a kindled rat. $A$, Intracellular response accompanied by an epileptiform component in simultaneously recorded surface field potential (top trace in $E$ ). $B$, Response when no epileptiform component was present in field potential (middle trace in $E$ ). $C$, Superimposed traces from $A$ and $B$. Note that a large depolarizing potential accompanies the surface positive component of the epileptiform field potential. This depolarizing potential is followed by a larger and longer-lasting hyperpolarizing potential than observed in responses without epileptiform components (right column). $D$, Same as $B$, but response that was suprathreshold for action potential generation (spike is truncated). $E$, Averaged field potentials recorded at the cortical surface with epileptiform event (top), no epileptiform event (middle), and superimposed event and no event trials (bottom). The same traces are illustrated at a fast sweep speed and high gain (left column) and slower sweep speed and lower gain (right column). All traces with the exception of those in $D$ are averages of three or more responses. Extracellular field potentials recorded immediately outside of the cell after electrode withdrawal were subtracted from records in $A-D$.

loop. First, the abrupt fall in depolarization suggests the presence of a shunting process like that associated with the $\mathrm{Cl}^{-}$-mediated IPSP in piriform cortex. Second, action potentials were usually evoked immediately before onset of the terminating process, but onset was not dependent on their occurrence in the impaled cell (compare Fig. 6C,D), consistent with previous findings for feedback inhibition in piriform cortex (Satou et al., 1982; Haberly and Bower, 1984; Tseng and Haberly, 1988). Third, the inhibitory process appeared to be inverted near resting membrane potential by injection of hyperpolarization current (Fig.
$8 A$ ), and peaked at approximately $20 \mathrm{msec}$ following EPSP onset (arrow in Fig. 8A), consistent with a $\mathrm{Cl}^{-}$-mediated IPSP (see Haberly and Bower, 1984; Tseng and Haberly, 1988).

Although the initial portion of the inhibitory process that accompanied epileptiform events appears to be a $\mathrm{Cl}^{-}$-mediated IPSP, the very long duration of the hyperpolarization $(600 \mathrm{msec}$ or more) and more negative reversal of the later portion suggest the presence of one or more longer-lasting processes mediated by $\mathrm{K}^{+}$. If this slow hyperpolarization were mediated endogenously by voltage-dependent currents such as $I_{\mathrm{AHP}}$ (Adams and 

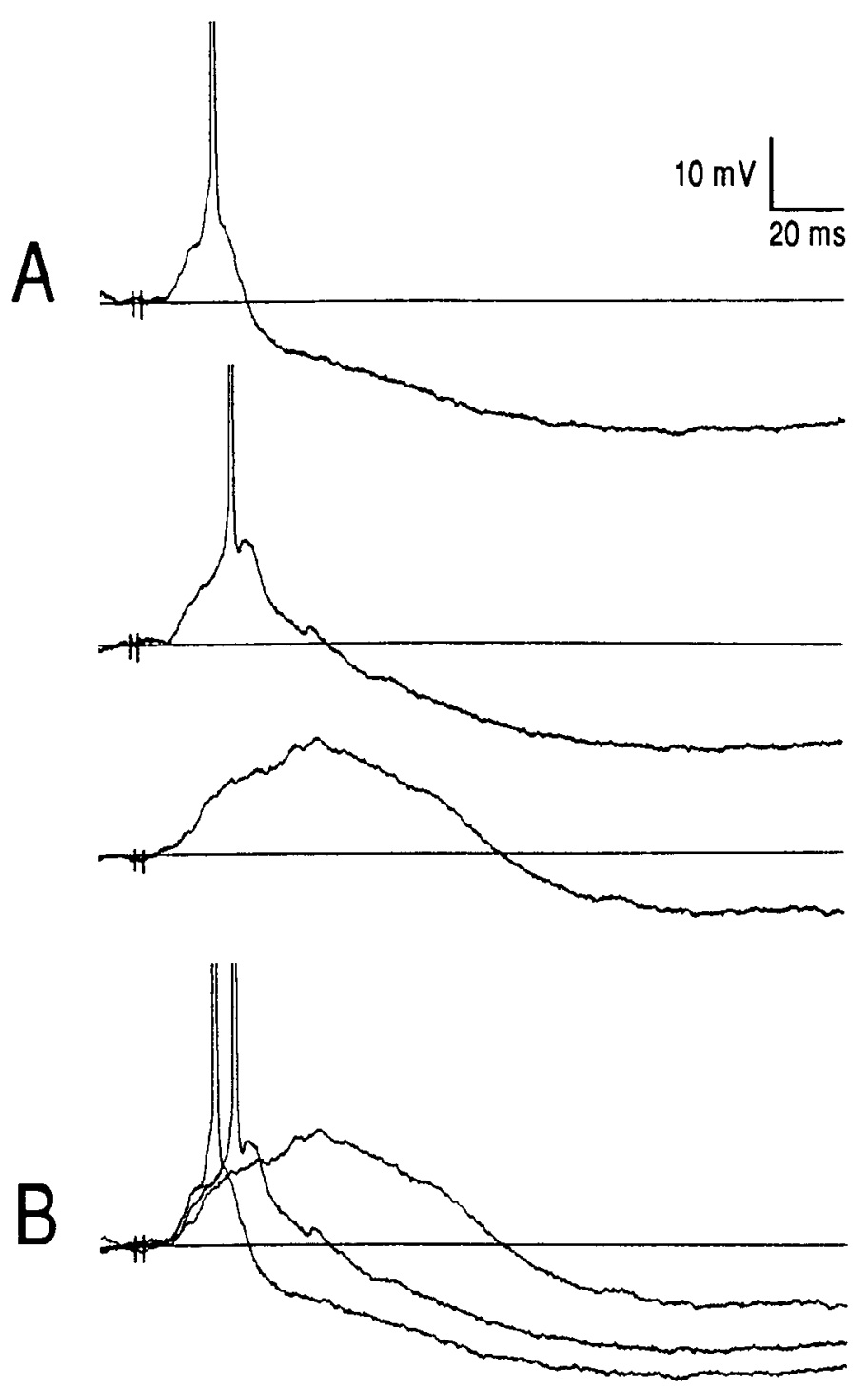

Q

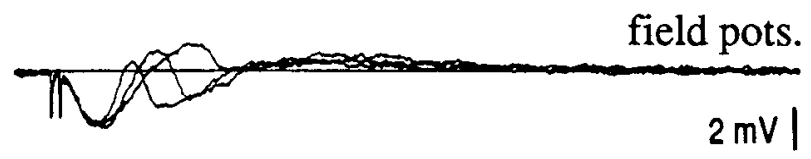

Figure 7. Change in intracellular potential with latency of epileptiform events. $A$, Intracellularly recorded responses from posterior piriform cortex that wcrc associated with extracellularly recorded epileptiform field potentials at three different latencies (traces in $C$ ). Latency increased from top to bottom. $B$, Superimposed traces from $A$. $C$, Surface field potentials recorded simultaneously with intracellular potentials in $A$ and $B$.

Galvan, 1986; Constanti and Sim, 1987; Tseng and Haberly, $1989 \mathrm{~b}$ ), amplitude and duration would likely be related to occurrence of action potentials and, perhaps, magnitude of the preceding cpilcptiform component. As illustrated in Figure 6, there was no apparent relationship between occurrence of action potentials on the epileptiform depolarization and amplitude or duration of the ensuing hyperpolarization. Further, no relationship was detected between amplitude of the epileptiform depolarization and strength of the hyperpolarization. In a small number of cells, slow hyperpolarizing potentials occurred in
A
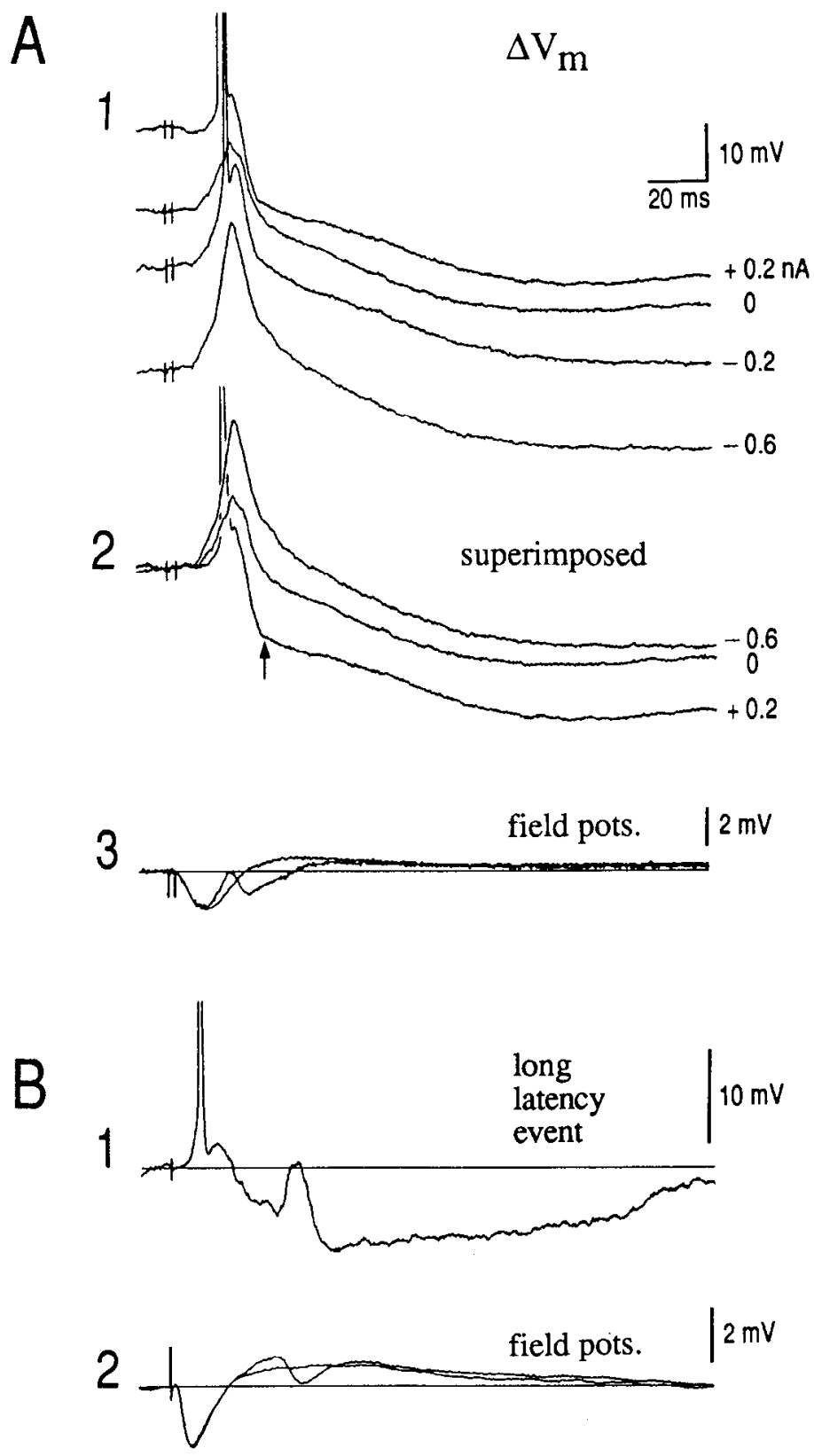

Figure 8. Effects of membrane potential on intracellularly recorded epileptiform events. $A 1$, Four responses during intracellular injection of indicated amounts of current. Responses were selected in which simultaneously recorded surface field potentials $(A 3)$ were nearly identical. Same cell as in Figure 7. A2, Superimposed traces from $A 1$. Action potential from the response with $+0.2 \mathrm{nA}$ has been retouched at crossover points for clarity. $A 3$, Averaged epileptiform field potentials simultaneously recorded with intracellular responses illustrated at top. Averaged trace from trials in which no epileptiform event was apparent is superimposed. Arrow in $A 2$ indicates probable $\mathrm{Cl}^{-}$-mediated IPSP (see Results). B1, Long-latency epileptiform event recorded in posterior piriform cortex that occurred during a hyperpolarizing IPSP. Different cell than illustrated in $A$. B2, Simultaneously recorded field potential superimposed on averaged nonepileptiform response. The time calibration at the top applies to all traces.

association with epileptiform events without a preceding depolarizing process.

A candidate for at least one component of the slow hyperpolarization accompanying epileptiform events is a $\mathrm{K}^{+}$-mediated IPSP (Satou et al., 1982; Tseng and Haberly, 1988). Evi- 
Figure 9. CSD analysis of response to $1 \mathrm{~Hz}$ LOT stimulation in control rat. $A$, Contour plot as a function of time and depth with inward currents (sinks) indicated by solid lines; outward currents (sources) are indicated by broken lines. Sinks are labeled according to the layers in which they are maximal. Roman numerals at left margin denote cortical layers. Layer I is the superficial plexiform layer where afferents terminate on distal apical dendritic segments of pyramidal cells (layer Ia) and intrinsic associational fibers terminate on more proximal apical segments (layer Ib). Layer II contains densely packed somata of superficial pyramidal cells, and layer III contains a lower density of deep pyramidal and multipolar cells and a dense neuropil that includes local axon collaterals and basal dendrites of pyramidal cells. $B$, Surface plot of same response as in $A$ with inward current in the upward direction and cortical surface (layer Ia) toward the back. $C$, Segment of surface plot in $B$ with cross section through the large source current in layer II. Time is $0-60 \mathrm{msec}$; depth is surface to layer II. $D$, Three averaged field potentials from the set of 63 used to compute CSD plots in $A-C$. Illustrated responses were recorded in layer I (top), layer II (middle), and layer III (bottom). $A$, and $B$, denote the monoand disynaptic components in period 1. Primary excitatory currents, as identified in previous studies, are the sink in layer Ia that generates the monosynaptic EPSP in distal apical dendrites followed by sinks in superficial layer Ib and layer III (small) that generate disynaptic EPSPs in proximal apical and basal dendrites of pyramidal cells. These sinks are coupled to passive source current centered in layer II.
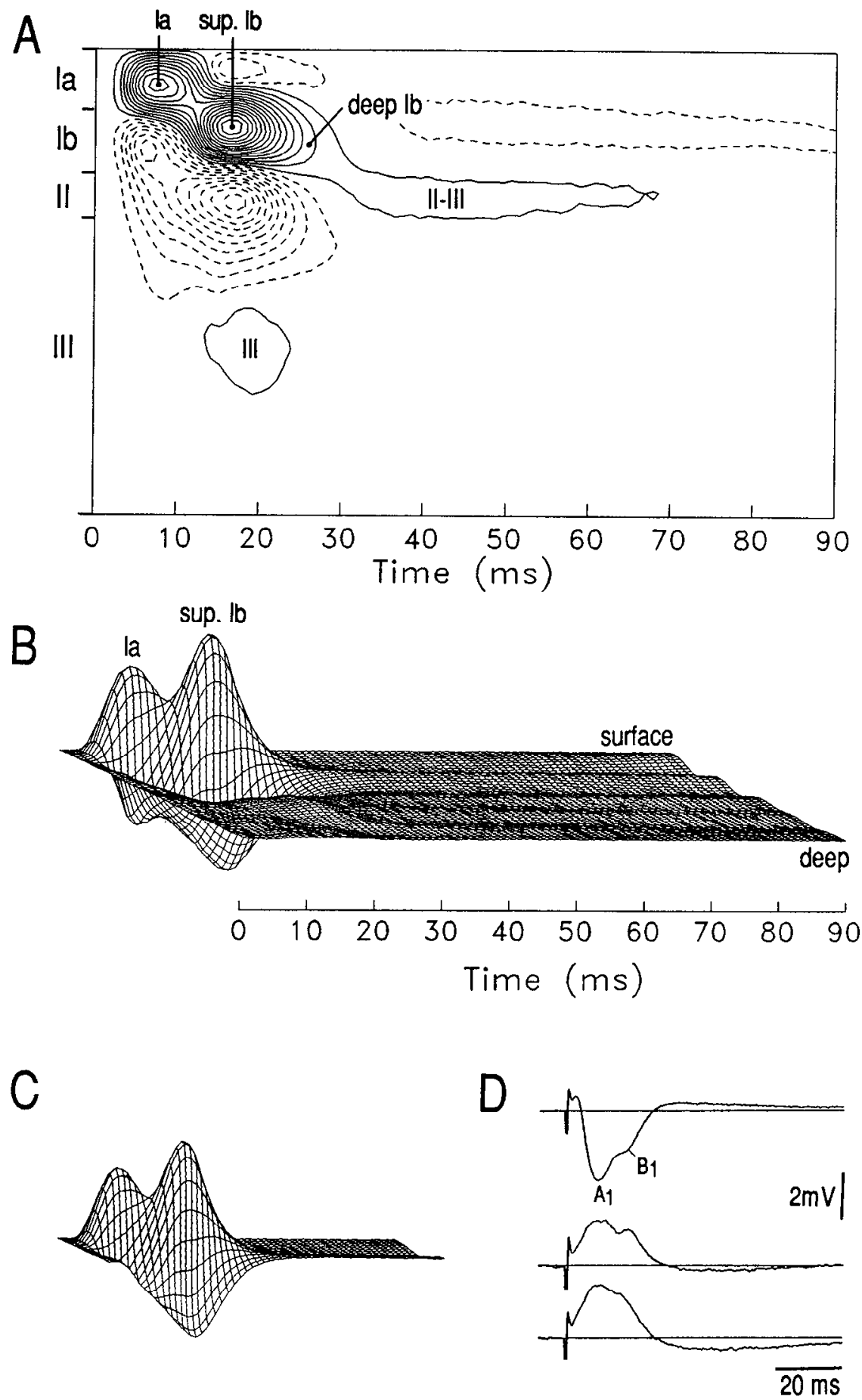

dence has been presented that this IPSP is generated in part by interneurons in a feedback loop in piriform cortex (Tseng and Haberly, 1988), suggesting that it is triggered along with the $\mathrm{Cl}^{-}$mediated IPSP by the firing of pyramidal cells during the initial depolarizing component of epileptiform rcsponses.

\section{Current source-density analysis}

CSD analysis was carried out on potentials recorded in 67 penetrations in four kindled animals in which stereotyped epileptiform events were evoked. Analysis was confined to periods 1 and 2 because insufficient resolution was obtained for visual- ization of the small currents in period 3. All membrane currents described were statistically significant in individual experiments at $p<0.05$ (see Materials and Methods) and consistently present in different animals. All penetrations were in posterior piriform cortcx bccausc of the relatively planar lamination. CSD analysis was confined to large epileptiform events initiated late in period 1 or during period 2 that could be consistently evoked in timelocked fashion. CSD analysis was also carried out on three unoperated control rats under conditions identical to those used for kindled rats (anesthesia, exposure sites, stimulus parameters, etc.). In addition, control CSD records were available from a 
much larger number of rats used in a different study (Ketchum and Haberly, 1988) under identical or nearly identical conditions.

CSD analysis in control animals. Net membrane currents evoked by LOT stimulation in a control animal are illustrated in Figure 9. As previously described for the opossum (Haberly and Shepherd, 1973; Rodriguez and Haberly, 1989) and rat (Moyano et al., 1985; Ketchum and Haberly, 1988; K. L. Ketchum and L. B. Haberly, unpublished observations), currents associated with monosynaptic and disynaptic EPSPs occur during period 1 of the field potential evoked by LOT stimulation. During the $A_{1}$ component of period 1 there is an initial sink (net inward membrane current) in layer Ia that is the current generating the monosynaptic EPSP in distal dendrites of pyramidal cells. During the $\mathrm{B}_{1}$ component there is a large sink centered in the superficial part of layer Ib ("sup. Ib" in Fig. 9A, $B$ ) and a smaller, longer-latency sink in the mid to deep part of layer III ("III" in Fig. 9A). The superficial Ib sink is mediated by long association axons originating primarily from pyramidal cells in anterior piriform cortex, and the layer III sink is mediated, at least in part, by local axon collaterals of pyramidal cells. The movement of peak inward current during the late part of the $\mathrm{B}_{1}$ component to the deep part of layer Ib ("deep Ib" in Fig. $9 A$ ) is belicved to correspond to later activation of pyramidal cells in posterior piriform cortex, and perhaps other areas, that project to a deeper zone in layer Ib than those in anterior piriform cortex. During the $A_{1}$ and $B_{1}$ components, outward currents (sources) in layer $\mathrm{Ib}$, then layers II and superficial III (broken lines in Fig. 9A), are believed to be largely passive return currents associated with the mono- and disynaptic EPSPs. Period 2 is dominated by a dipole consisting of an inward current in layer II-superficial III ("II-III" in Fig. 9A) and an outward current in layer I that is thought to be associated with IPSP generation.

Responses to weak shocks in kindled rats that did not evoke epileptiform events were qualitatively similar to control responses. However, detailed comparisons could not be made because, even at low shock strengths, it was not possible to obtain a sufficient number of nonepileptiform responses to permit high-rcsolution CSD analysis.

CSD analysis of epileptiform events. Membrane currents in the early part of period 1 appeared qualitatively normal, but clear abnormalities at longer latency were apparent (Figs. 10, 11). A striking change was a large decrease in the amplitude of the superficial $\mathrm{Ib}$ sink that is prominent in control responses (compare Figs. $9 A, 10 A$ ). Since it was not possible do accurate CSD analysis on nonepileptiform responses in kindled animals, it was not clear to what extent this decrease was the result of inhibitory processes triggered by the occurrence of epileptiform events that can block generation of this sink in control animals by inhibition of firing in pyramidal cells that mediate it (Rodriguez and Haberly, 1989; Ketchum and Haberly, unpublished observations) as opposed to a change induced by the kindling process. While the superficial lb sink was suppressed, a smaller sink focused in the deep part of layer Ib was consistently present late in period 1 in epileptiform responses. This sink continued until appearance of the large membrane currents associated with the peak of the epileptiform event.

For epileptiform events that were initiated near the period $1-$ 2 transition, the prominent spike-like deep negative component of the field potential was associated with a sink distributed over the deep part of layer Ib, layer II, and layer III ("Ib,II,III epilep." in Fig. 10). In layers II and III this sink abruptly interrupted the large source current associated with the layer Ia and superficial Ib sinks (compare Figs. 9C, 10C). In layer Ib, the deep sink described above that is decreasing in amplitude late in period 1, starts to increase at the same time. The broad distribution over depth of the Ib, II, III epileptiform sink is responsible for the disproportionately large associated deep negative field potential. Since the epileptiform EPSP as observed intracellularly occurs during this field potential component, it can be concluded that the inward current plays a role in its generation. Action potentials that were observed in extracellular recordings in layers II and III during the Ib, II, III epileptiform sink also presumably contributed to the inward current, but the extent of this contribution is undetermined.

Since associational projections in piriform cortex have been shown to originate from pyramidal cells (Haberly and Price, 1978; Haberly, 1985) and to mediate an excitatory action (Haberly and Bower, 1984; Tseng and Haberly, 1988), the firing of pyramidal cells during the epileptiform EPSP (Figs. 6-8) would be expected to mediate strong inward currents at the depth of termination of their extensive axonal arbors. Anatomical studies have shown that associational projections from cells in posterior piriform cortex are concentrated in layers Ib and III, with the projection to layer $\mathrm{Ib}$ focused at a greater depth than that from anterior piriform cortex that mediates the prominent sink in superficial Ib in control animals. As illustrated in the contour plot in Figure 10A, sinks at the predicted depths ("Ib epilep." and "III epilep.") were observed following the Ib, II, III epileptiform sink with which action potential generation was associated. The Ib epileptiform sink peaked at greater depth than the superficial Ib sink in control animals. There was also a shift in depth of the peak of the Ib epileptiform sink in all experiments as it progressed in time. This shift typically was from the deep part of layer Ib to the middle or superficial part and back to the deep part, perhaps reflecting propagation of epileptiform firing to different parts of olfactory cortex that terminate at different depths in this layer (Luskin and Price, 1983b).

The onset of period 2 currents was delayed in kindled animals, and their amplitudes increased relative to control animals, but both sinks and sources during period 2 peaked at approximately the same depths as in controls.

Membrane currents visualized by CSD analysis during relatively long-latency kindled epileptiform events (mid to late period 2) (Fig. 11) were similar to those observed at shorter latency with one important exception: the Ib, II, III epileptiform sink displayed a slow rather than abrupt onset. This sink was most apparent in the superficial part of layer III (Fig. $11 \mathrm{~B}$ ), but it was also present in layer II, and appeared to add to the tail of the deep Ib sink as described for the shorter-latency event in Figure 10. This ramp appeared to start relatively early in period 1 and became a net inward current at $20-25 \mathrm{msec}$ latency. For the event illustrated in Figure 11, a sharply peaked sink occurred in layer II following the ramplike current. This sink appeared to be sufficiently fast to be associated with action potential generation.

\section{Discussion}

The present study of kindled rats has shown that interictal-like epileptiform events resembling those recorded in unanesthetized animals can be reliably evoked in a urethane anesthetized preparation, allowing detailed physiological study. The combined analysis of membrane potential and current has provided 


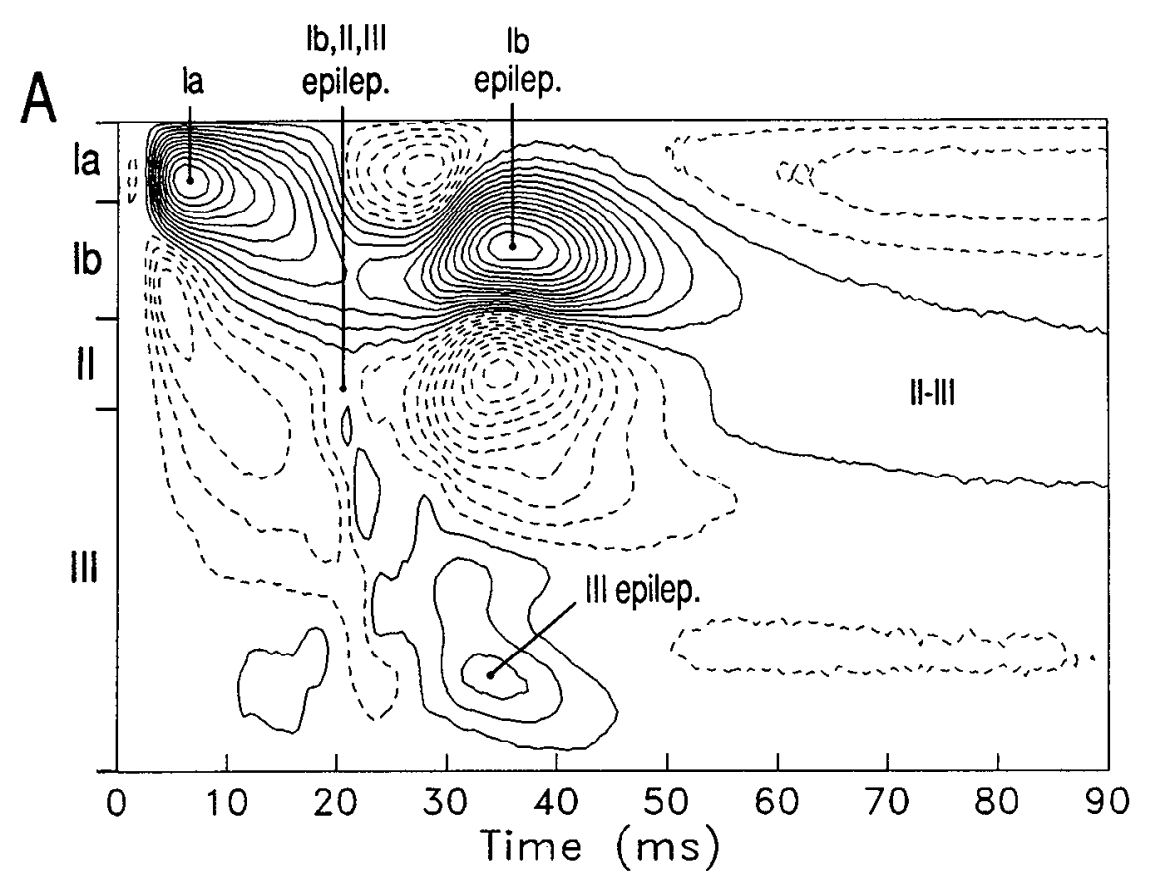

Figure 10. CSD analysis of response to $1 \mathrm{~Hz}$ LOT stimulation in a kindled rat with a relatively brief latency epileptiform event. $A$, Contour plot as in Figure $9 A$ with sinks labeled according to the layers in which they peak. $B$, Surface plot of same data. $C$, Segment of surface plot in $B$ with section at the layer II/III border; time is $0-60 \mathrm{msec}$. $D$, Field potentials recorded in layer I (top), layer II (middle), and layer III (bottom) from the series used to compute CSD in $A-C$. The primary changes in comparison with the normal control illustrated in Figure 9 are the loss of the disynaptic sink in the superficial part of layer $\mathrm{Ib}$, and the appearance of abnormal currents associated with the prominent deep negative and deep positive epileptiform field potential components. The deep negative component is generated by a sink distributed over layers Ib, II, and III (Ib,II,III epilep.) that sharply interrupts the large source current in layers II and III (best seen in $C)$. The deep positive component is associated with large sinks in layers $\mathrm{Ib}$ and III (Ib epilep. and III epilep., respectively) coupled to source current centered in layer II.
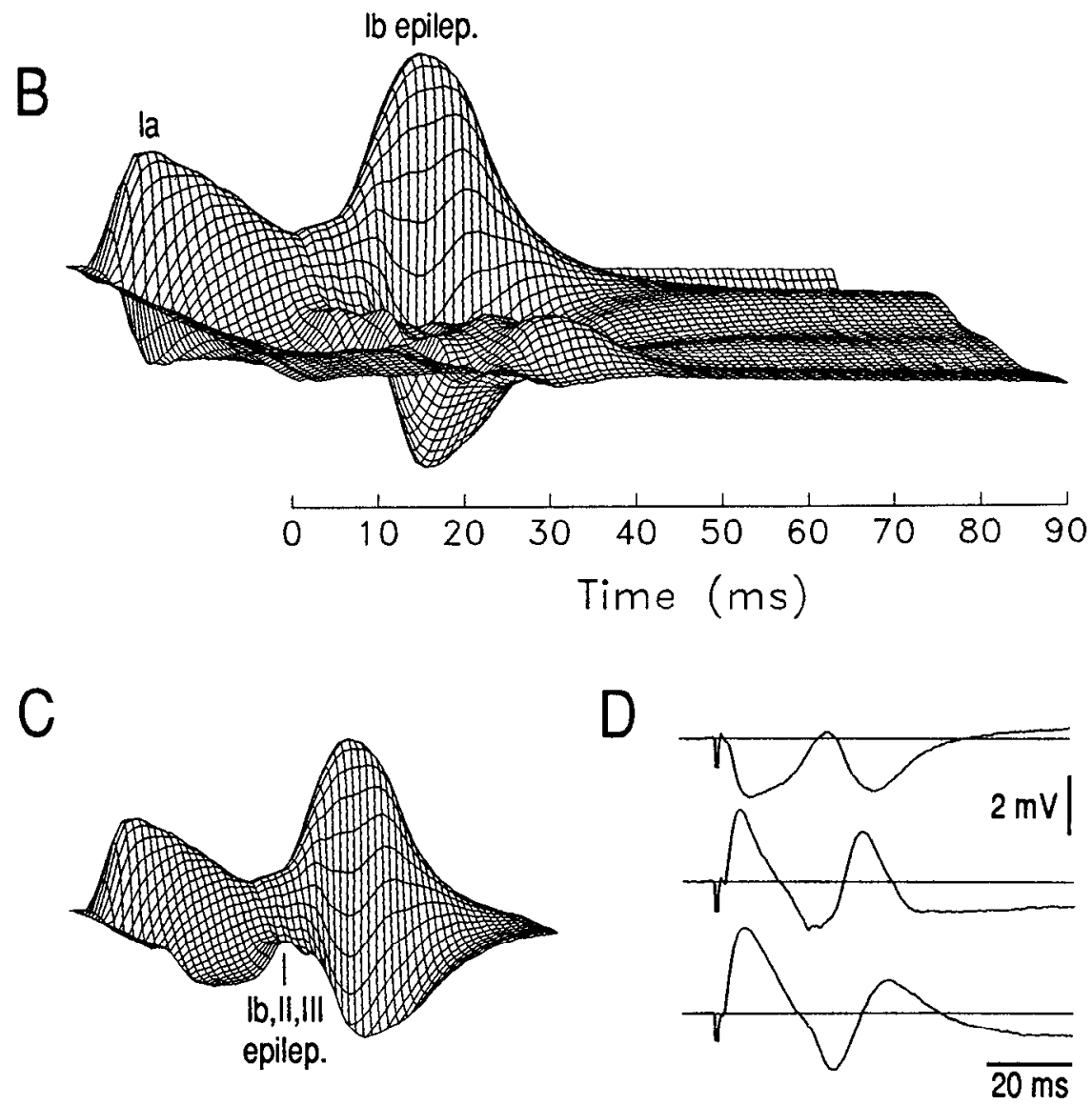

a rather complete picture of the sequence of neuronal events that underlies expression of these epileptiform events.

Sequence of membrane potentials and currents associated with kindled epileptiform events

In intracellular recordings from pyramidal cells, epileptiform events consisted of an initial EPSP that evoked spikes, and a rapidly rising IPSP that limited spiking to singlc action potentials. This brief epileptiform EPSP contrasts sharply with the "depolarizing shift" associated with interictal events induced by disinhibition in the intact neocortex (Matsumoto and Marsan, 1964), hippocampal cortex (Dichter and Spencer, 1969), and piriform cortex (Haberly and Bower, 1984) that evokes bursts of action potentials. 

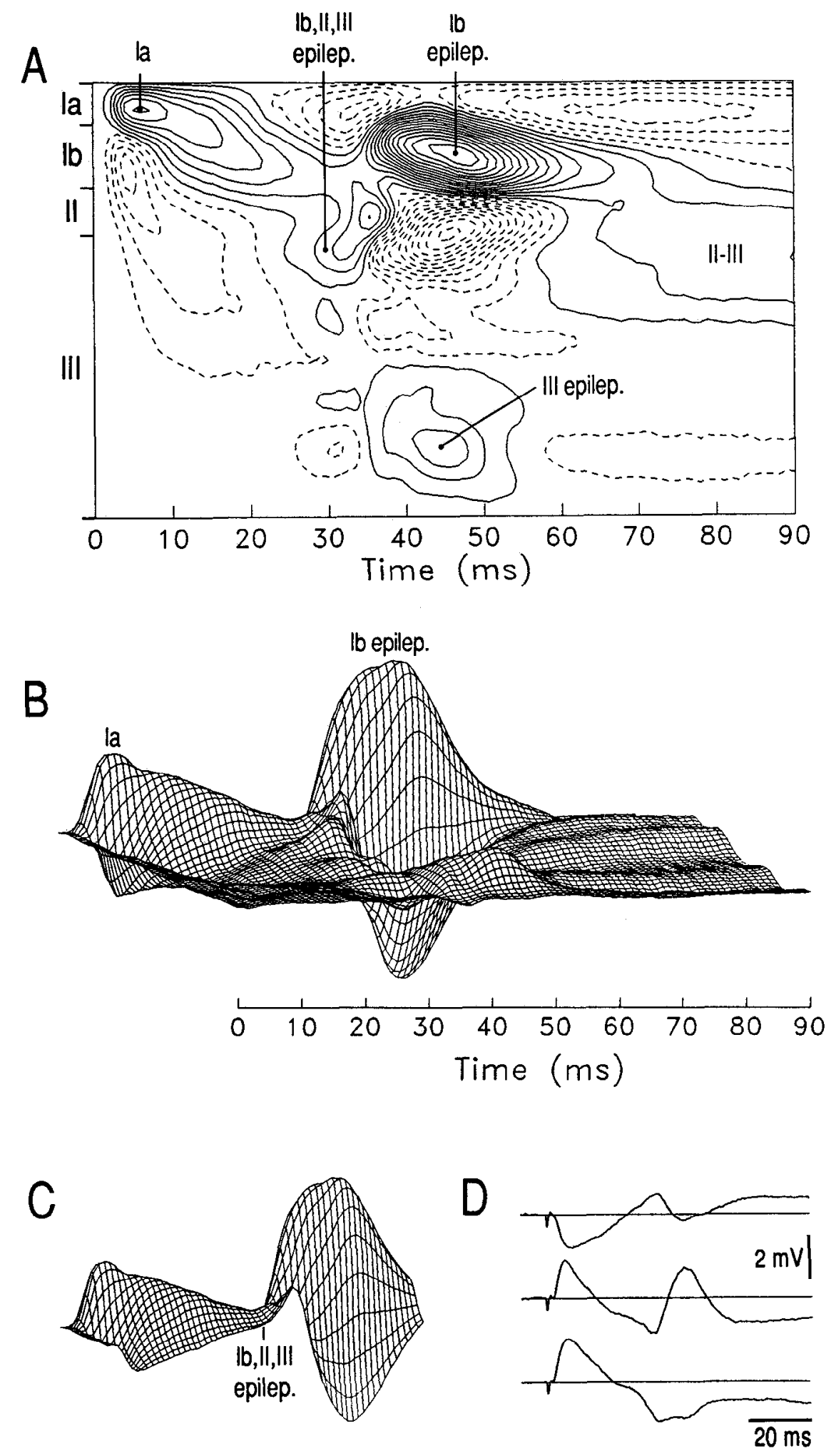

Figure 11. CSD analysis of response to $0.3 \mathrm{~Hz}$ LO'l stimulation in a kindled rat with a relatively long-latency epileptiform event. Presentation in $A-D$ is same as in Figure 10. Note that the Ib, II, III epileptiform sink builds up slowly rather than abruptly as in the shorterlatency event in Figure 10 (best seen in $B$ and $C$ ).
CSD analysis revealed a clearly abnormal sink extending from the deep part of layer Ib through layer III that was consistently correlated in time with the initiation of the epileptiform EPSP as recorded intracellularly. Following the firing of action potentials, there was an abrupt shift in the laminar distribution of membrane current: the shift was from inward currents in layers Ib, II, and III, coupled to outward current in layer Ia, to spatially separated sinks in layers Ib and III, coupled with an intervening source centered in layer II. As described in Results, this latter pattern likely represents excitatory postsynaptic currents (EPSCs) in apical and basal dendrites of pyramidal cells in layers Ib and III, respectively, that are coupled to passive outward current in cell bodies concentrated in layer II. These currents presumably occur in other cell types as well; however, as previously dis- 
cussed (Rodriguez and Haberly, 1989), net membranc currents detected by CSD analysis in piriform cortex are largely associated with pyramidal cells as a consequence of the extended geometry of their dendritic trees. Concomitant inhibition may have altered the depth distribution of the outward return current for the EPSC, but given the relatively small net currents associated with IPSPs (Mitzdorf, 1985; Ketchum and Haberly, unpublished observations), it is unlikely that they contributed substantially to the observed sinks. Examination of intracellularly recorded potentials at the time of occurrence of the large postspiking sinks yields the rather surprising conclusion that shunting and hyperpolarization associated with IPSPs completely blocked the spread of EPSPs generated by these sinks to the cell body in most cases. Only when the fast IPSP failed to occur (Fig. 7), perhaps as a consequence of the absence of population firing by pyramidal cells at the recording site, could the presence of this excitatory process be directly observed intracellularly.

IPSPs could be studied by CSD analysis only from approximately $50 \mathrm{msec}$ (termination of obscuring EPSPs) to $150 \mathrm{msec}$ (limit of statistically significant signal). In this window, distribution over depth of generating currents was indistinguishable from that associated with period 2 in control animals. This suggests that early inhibitory components are qualitatively similar in kindled and normal animals.

\section{Mechanism of generation of kindled epileptiform events}

Although the present studies in vivo are largely of value for study of the mechanism of expression of kindled epileptiform events, clues to the underlying initiation processes have been obtained.

One obvious clue is the finding that an EPSP underlies the depolarizing process that drives epileptiform spiking in pyramidal cells. In studies of epileptiform potentials in slices induced by bursting activity in vitro (Hoffman and Haberly, 1989a,b, 1991a) and by kindling prior to slice preparation (Hoffman and Haberly, 1991b), a similar conclusion was reached. A central question is the identity of the cells that drive the initial epileptiform EPSP. In the slice preparation it was shown by a number of manipulations that are not possible in vivo that this EPSP is driven by deep cells in the endopiriform nucleus and ventral claustrum, subjacent to the piriform cortex and, perhaps, in the deep part of layer III of piriform cortex (Hoffman and Haberly, $1991 \mathrm{a}, \mathrm{b})$. The only evidence from the present study bearing on this question is the laminar distribution of inward current as revealed by CSD analysis. Unfortunately, as described in Results, overlap of the epileptiform EPSC with nonepileptiform EPSCs and currents associated with relatively synchronous action potential generation and perhaps other voltage-dependent currents precluded definite conclusions.

Three other characteristics of the generation process provide further clues concerning its mechanism. First, the synaptic drive onto pyramidal cells that initiates epileptiform events tends to occur in an all-or-none fashion. This clearly establishes the presence of a synchronizing process that allows a large ensemble of the driving cells to fire within a brief time window to mediate the initial phase of the epileptiform EPSP. In slice studies (Tseng and Haberly, 1989a,b; Hoffman and Haberly, 1991a,b) it has been shown that cells at the deep boundary of piriform cortex have this property. Indirect evidence suggests that synchronized epileptiform firing is a consequence, at least in part, of reverberating positive feedback in direct excitatory connections in deep cell populations.

A second characteristic of the generation process is that it can drive epileptiform EPSPs at long delays from the cvoking stimulus. Delays on the order of $10 \mathrm{msec}$ from the normal latency of pyramidal cell firing were typical, but could be $50 \mathrm{msec}$ or longer. In modeling studies of epileptiform activity in hippocampal cortex it has been shown that delays on this order can be introduced as a consequence of a slow onset of reverberating positive feedback (Traub and Dingledine, 1990). It has also been speculated (Hoffman and Haberly, 1989a) that an endogenous regenerative potential in deep cells in the piriform cortex and endopiriform nucleus (Tseng and Haberly, 1989a), thought to be mediated by $\mathrm{Ca}^{2+}$ (Tseng and Haberly, 1989b), may also contribute to the delay.

A third characteristic that offers potential insight into the mechanism of generation is that initiation of epileptiform EPSPs can occur during the time period in which IPSPs block action potential initiation in pyramidal and deep nonpyramidal cells in control animals (Haberly and Bower, 1984; Tseng and Haberly, 1988, 1989a). This inhibition prevents firing in response to the second of a pair of shocks separated by $30 \mathrm{msec}$ in control animals, yet in kindled animals the occurrence of epileptiform spikes is enhanced at this interval (Fig. 3B). Clearly, at least certain inhibitory processes are intact in kindled animals as evidenced by the presence of strong IPSPs in nonepileptiform (Fig. $6 B$ ) and epileptiform (Fig. 6A) responses. These IPSPs are sufficiently strong and fast to limit firing of pyramidal cells consistently during interictal events to single action potentials. However, it would appear that either the synchronization process that drives interictal spikes is insensitive to this inhibition or the short-latency inhibition associated with nonepileptiform responses is impaired in kindled animals.

\section{Does epileptiform activity propagate within piriform cortex?}

On the basis of the results obtained by simultaneous two-site recording, it can be postulated that epileptiform events in kindled animals can propagate from posterior to anterior within the piriform cortex. This hypothesis is suggested by the finding that infrequently occurring epileptiform events in posterior piriform cortex are followed by epileptiform events in anterior piriform cortex at a relatively consistent delay, regardless of absolute latency. Furthermore, conduction velocities computed from delays with the assumption that propagation has occurred are in the range of conduction velocities of the fine-caliber long associational axons within the piriform cortex (Haberly, 1978). The finding that anterior events can be larger and faster in waveform than preceding posterior events suggests that the allor-none generation process is propagating, as opposed to a nonregenerative postsynaptic potential driven by an axonal volley from an epileptiform event confined to posterior piriform cortex. The possibility must also be considered that epileptiform activity is originating outside the piriform cortex and propagated to posterior piriform cortex by a shorter or faster pathway than to anterior piriform cortex.

\section{Relationship of interictal-like epileptiform events to kindled seizures}

The interictal epileptiform activity examincd in the present study is highly restricted temporally and clearly has no direct relationship to behaviorally observed seizures in kindled animals. However, the new insights into the neuronal activity that underlies these abnormal potentials do allow the formulation of hypotheses concerning seizure generation. One relevant finding is that the brief epileptiform events trigger strong volleys in the 
association fibers that originate from and terminate on pyramidal cells. This was revealed as the large EPSC in layers Ib and III following epileptiform firing of pyramidal cells. A second finding relevant to understanding seizure generation is that the strong feedback IPSP blocks initiation of action potentials by this excitatory current. It follows that any impairment of this IPSP could lead to sustained seizure activity, since the associational fibers in piriform cortex constitute a positive feedback loop in the pyramidal cell population that could drive a reverberating self-excitation. It can be speculated that the stimulus trains used to trigger seizures in kindled animals have this disinhibitory action. Such "frequency disinhibition" has been demonstrated in other areas of cerebral cortex as a consequence of a number of processes including a shift in $\mathrm{Cl}^{-}$equilibrium potential, receptor desensitization, channel phosphorylation, and presynaptic inhibition via $\mathrm{GABA}_{\mathrm{B}}$ receptors (McCarren and $\mathrm{Al}$ ger, 1985; Huguenard and Alger, 1986; Deisz and Prince, 1989; Thompson and Gähwiler, 1989a-c; Chen et al., 1990).

It is important to note that the association fibers from pyramidal cells in piriform cortex are distributed over widespread portions of the basal forebrain. These fibers provide heavy direct projections to a number of areas that are prone to complex partial seizures (Delgado-Escueta et al., 1986), including insular and orbitofrontal areas of neocortex, the amygdala, and the entorhinal cortex, which is the major input to the hippocampus (Luskin and Price, 1983a; Price, 1985; Takagi, 1986). As a consequence, epileptiform activity occurring in the piriform cortex could be widely disseminated.

\section{References}

Adams PR, Galvan M (1986) Voltage-dependent currents of vertebrate neurons and their role in membrane excitability. In: Advances in neurology, Vol 44 (Delgado-Escueta AV, Ward AA Jr, Woodbury DM, Porter RJ, eds), pp 137-170. New York: Raven.

Biedenbach MA, Stevens CF (1969) Synaptic organization of the cat olfactory cortex as revealed by intracellular recording. J Neurophysiol 32:204-214.

Chen QX, Stelzer A, Kay AR, Wong RKS (1990) GABA $_{A}$ receptor function is regulated by phosphorylation in acutely dissociated guineapig hippocampal neurones. J Physiol (Lond) 420:207-221.

Constanti A, Sim JA (1987) Calcium-dependent potassium conductance in guinea-pig olfactory cortex neurones in vitro. J Physiol (Lond) 387:173-194.

Croucher MJ, Bradford HF, Sunter DC, Watkins JC (1988) Inhibition of the development of electrical kindling of the prepyriform cortex by daily focal injections of excitatory amino acid antagonists. Eur $\mathbf{J}$ Pharmacol 152:29-38.

Deisz RA, Prince DA (1989) Frequency-dependent depression of inhibition in guinea-pig neocortex in vitro by $\mathrm{GABA}_{\mathrm{B}}$ receptor feedback on GABA release. J Physiol (Lond) 412:513-541.

Delgado-Escueta AV, Ward AA Jr, Woodbury DM, Porter RJ (1986) New wave of research in the epilepsies. In: Advances in neurology, Vol 44 (Delgado-Escueta AV, Ward AA Jr, Woodbury DM, Porter RJ, eds), pp 3-55. New York: Raven.

Dichter M, Spencer WA (1969) Penicillin-induced interictal discharges from the cat hippocampus. I. Characteristics and topographical features. J Neurophysiol 32:649-662.

Goddard GV, Mclntyre DC, Leech CK (1969) A permanent change in brain function resulting from daily electrical stimulation. Exp Neurol 25:295-330.

Haberly LB (1973) Summed potentials evoked in opossum prepyriform cortex. J Neurophysiol 36:775-778.

Haberly LB (1978) Application of collision testing to investigate properties of multiple association axons originating from single cells in the piriform cortex of the rat. Soc Neurosci Abstr 4:75.

Haberly LB (1985) Neuronal circuitry in olfactory cortex: anatomy and functional implications. Chem Senses 10:219-238.

Haberly LB, Bower JM (1984) Analysis of association fiber system in piriform cortex with intracellular recording and staining methods. J Neurophysiol 51:90-112.

Haberly LB, Bower JM (1989) Olfactory cortex: model circuit for study of associative memory? Trends Neurosci 12:258-264.

Haberly LB, Price JL (1978) Association and commissural fiber systems of the olfactory cortex of the rat. I. Systems originating in the piriform cortex and adjacent arcas. J Comp Ncurol 178:711-740.

Haberly LB, Shepherd GM (1973) Current density analysis of opossum prepyriform cortex. J Neurophysiol 36:789-802.

Haberly LB, Hansen DJ, Feig SL, Presto S (1987) Distribution and ultrastructure of neurons in opossum displaying immunoreactivity to GABA and GAD and high affinity tritiated GABA uptake. J Comp Neurol 266:269-290.

Hoffman WH, Haberly LB (1989a) Bursting induces persistent all-ornone EPSPs by an NMDA-dependent process in piriform cortex. $J$ Neurosci 9:206-215.

Hoffman WH, Haberly LB (1989b) Do changes in synaptic excitation or inhibition underlie generation of long-lasting bursting-induced late EPSPs in piriform cortex? Soc Neurosci Abstr 15:700.

Hoffman WH, Haberly LB (1991a) Bursting induced epileptiform EPSPs in slices of piriform cortex are gencrated in decp cells. J Ncurosci 11:2021-2031.

Hoffman WH, Haberly LB (1991b) Epileptiform potentials in slices of piriform cortex from kindled rats originate in deep structures. Soc Neurosci Abstr 17:511.

Huguenard JR, Alger BE (1986) Whole-cell voltage-clamp study of the fading of GABA-activated currents in acutely dissociated hippocampal neurons. J Neurophysiol 56:1-18.

Kairiss EW, Racine RJ, Smith GK (1984) The development of the interictal spike during kindling in the rat. Brain Res 322:101-110.

Kandel ER, Spencer WA, Brinley FJ (1961) Electrophysiology of hippocampal neurons. I. Sequential invasion and synaptic organization. J Neurophysiol 24:225-242.

Ketchum KL, Haberly LB (1988) CSD analysis of oscillatory responses in rat piriform cortex reveals stercotyped cyclical components mediated by afferent and intrinsic association fibers. Soc Neurosci Abstr 14:278.

King GL, Dingledine R, Giacchino JL, McNamara JO (1985) Abnormal neuronal excitability in hippocampal slices from kindled rats. J Neurophysiol 54:1295-1304.

Luskin MB, Price JL (1983a) The topographic organization of associational fibers of the olfactory system in the rat, including centrifugal fibers to the olfactory bulb. J Comp Neurol 216:264-291.

Luskin MB, Price JL (1983b) The laminar distribution of intracortical fibers originating in the olfactory cortex of the rat. J Comp Neurol 216:292-302

Matsumoto H, Marsan CA (1964) Cortical cellular phenomena in experimental epilepsy: interictal manifestations. Exp Neurol 9:286304.

McCarren M, Alger BE (1985) Use-dependent depression of IPSPs in rat hippocampal pyramidal cells in vitro. J Neurophysiol 53:557571.

McIntyre DC, Wong RKS (1986) Cellular and synaptic properties of amygdala-kindled pyriform cortex in vitro. J Neurophysiol 55:12951307.

Mitzdorf U (1985) Current source-density method and application in cat cerebral cortex: investigation of evoked potentials and EEG phenomena. Physiol Rev 65:37-100.

Moyano HF, Cinelli AR, Molina JC (1985) Current generators and properties of early components evoked in rat olfactory cortex. Brain Res Bull 15:237-248.

Piredda S, Gale K (1985) A crucial epileptogenic site in the deep prepiriform cortex. Nature 317:623-625.

Piredda S, Gale K (1986) Role of excitatory amino acid transmission in the genesis of seizures elicited from the deep prepiriform cortex. Brain Res 377:205-210.

Price JL (1985) Beyond the primary olfactory cortex: olfactory-related areas in the neocortex, thalamus and hypothalamus. Chem Senses 10: 239-258.

Racine RJ, Milgram MW, Hafner S (1983) Long-term potentiation phenomena in the rat limbic forebrain. Brain Res 260:217-231.

Racine RJ, Mosher M, Kairiss EW (1988) The role of the pyriform cortex in the generation of interictal spikes in the kindled preparation. Brain Res 454:251-263.

Rodriguez R, Haberly LB (1989) Analysis of synaptic events in the 
opossum piriform cortex with improved current source density techniques. J Neurophysiol 61:702-718.

Russell RD, Stripling JS (1985) Effect of olfactory bulb kindling on evoked potentials in the pyriform cortex. Brain Res 361:61-69.

Satou M, Mori K, Tazawa Y, Takagi SF (1982) Two types of postsynaptic inhibition in pyriform cortex of the rabbit: fast and slow inhibitory postsynaptic potentials. J Neurophysiol 48:1142-1156.

Scholfield CN (1978) A depolarizing inhibitory potential in neurones of the olfactory cortex in vitro. J Physiol (Lond) 275:547-557.

Stevens JR, Phillips I, Beaurepaire R (1988) $\gamma$-Vinyl GABA in endopiriform area suppresses kindled amygdala seizures. Epilepsia 29: 404-411.

Sutula T, Steward O (1986) Quantitative analysis of synaptic potentiation during kindling of the perforant path. J Neurophysiol 56:732745.

Takagi SF (1986) Studies on the olfactory nervous system in the old world monkey. Prog Neurobiol 27:195-250.

Thompson SM, Gähwiler BH (1989a) Activity dependent disinhibition. I. Repetitive stimulation reduces IPSP driving force and conductance in the hippocampus in vitro. J Neurophysiol 61:501-511.
Thompson SM, Gähwiler BH (1989b) Activity dependent disinhibition. II. Effects of extracellular potassium, furosemide, and membrane potential on $E_{\mathrm{CI}}$ in hippocampal CA3 neurons. J Neurophysiol 61: 512-523.

Thompson SM, Gähwiler BH (1989c) Activity dependent disinhibition. III. Desensitization and $\mathrm{GABA}_{\mathrm{B}}$ receptor-mediated presynaptic inhibition in the hippocampus in vitro. J Neurophysiol 61:524-533.

Traub RD, Dingledine R (1990) Model of synchronized epileptiform bursts induced by high potassium in CA3 region of rat hippocampal slice. Role of spontaneous EPSPs in initiation. J Neurophysiol 64: 1009-1018.

Tseng G-F, Haberly LB (1988) Characterization of synaptically mediated fast and slow inhibitory processes in piriform cortex in an in vitro slice preparation. J Neurophysiol 59:1352-1376.

Tseng G-F, Haberly LB (1989a) Deep neurons in piriform cortex. I. Morphology and synaptically evoked responses including a unique high amplitude paired shock facilitation. J Neurophysiol 62:369-385.

Tseng G-F, Haberly LB (1989b) Deep neurons in piriform cortex. II. Membrane properties that underlie unusual synaptic responses. J Neurophysiol 62:386-400. 